\title{
Prevalence Patterns of Allergen Sensitization in Different Regions, Sexes, Ages and Seasons in Mainland China: A Four-year Multicenter Study
}

\author{
Wenting Luo ${ }^{1}$, Dandan Wang ${ }^{2}$, Teng Zhang ${ }^{2}$, Peiyan Zheng ${ }^{1}$, Dongliang Leng ${ }^{2}$, Ling Li $^{3}$, \\ Yong $\mathrm{Liu}^{3}$, Baoqing Sun ${ }^{1}$, and Xiaohua Douglas Zhang ${ }^{2}$ \\ ${ }^{1}$ Guangzhou Medical University \\ ${ }^{2}$ University of Macau \\ ${ }^{3}$ Guangzhou Kingmed Diagostics Group Co., Ltd
}

July 16, 2020

\begin{abstract}
Background: The proportion of the population with allergic diseases has increased rapidly in recent decades. Studies on the prevalence of allergens contribute to the treatment and prevention of allergic diseases. Although many studies have been published on the prevalence of allergens in China, there are limited studies on the geographic distribution of allergens. Objective: The aim of this study was to explore the prevalence patterns of sensitization to allergens among patients with allergic diseases in all the seven geographic regions of mainland China. Methods: A large epidemiological study was conducted on the prevalence patterns of serum allergen-specific IgE ( $\mathrm{sIgE}$ ) sensitization to the four most common food allergens and five aeroallergens among 44156 patients with allergic symptoms from 2015 to 2018. The data were analyzed using the chi-square test, and descriptive statistics, forest plots and geographic heatmaps. Results: First, house dust mites were the allergen with the highest prevalence of sensitization in all seven regions, with the highest in South China (40.79\%) and the lowest prevalence in Northeast China $(11.21 \%)$. The prevalence of allergens varied in different regions and seasons. Second, the prevalence of sensitization was significantly higher among male than female subjects. Third, except for egg whites and milk, which had the highest positive rates in children, sensitization to other allergens tended to be the highest in teenagers and young adults. Conclusions: Our findings could help clinical staff apply effective treatment to unique patient groups and direct researchers to conduct deeper studies on the epidemiology of allergic diseases.
\end{abstract}

\section{Keywords}

allergens and epitopes, epidemiology, food allergy, IgE

\section{Introduction}

Allergy, one of the most common types of hypersensitivity diseases, typically includes asthma, hay fever, atopic eczema and food allergies and may cause symptoms such as eye redness, sneezing, runny nose and even death. In recent decades, the incidence of allergic diseases has increased annually worldwide ${ }^{1-3}$. For example, the estimated rates of food allergies increased from $3.5 \%$ to $6 \%$ in the United Sates ${ }^{4}$. The prevalence of asthma in American adults increased from $7.21 \%$ in 2000 to $8.52 \%$ in 2009, and one study speculated an increase in the number of patients aged older than 14 years with asthma in mainland China ${ }^{5}$. In addition to affecting the quality of life, a significant economic burden of these diseases was transferred to society and the national health care system ${ }^{4}$. Allergy is caused by exaggerated immune sensitivity to certain environmental substances (called allergens), which are usually food, plants, animals, insects and so on. Therefore, the study of the prevalence of sensitization to allergens is key for preventing and treating allergic diseases. 
Many studies have focused on the prevalence of allergens and found an increase in the prevalence of allergies. The increase was found to be associated with economic improvement, lifestyle, climate change, and geographical and seasonal variations ${ }^{6,7}$. China is a large country with a rapidly developing economy, wide geography, and a diverse climate and diverse lifestyles. Although a series of studies have explored the prevalence of allergen sensitization in China, the majority of them focus on one part of geography in China $^{8,9}$. In 2009, a study was conducted to estimate the prevalence of 13 common aeroallergens among patients with allergic asthma and/or rhinitis in mainland China ${ }^{6}$. Although the study investigated the differences in the prevalence and pattern of allergen sensitizations in four regions of China, it only paid attention to aeroallergens and did not consider food allergens. In this study, the skin prick test (SPT) was used to detect the sensitization to allergens. The method has low accuracy for positive results because it is heavily affected by certain factors, such as the skill of the tester, reagent used, interpretation of results and so on ${ }^{10}$. Furthermore, dividing China into only four regions may neglect detailed information about the characteristics of sensitization prevalence in different places in China. Therefore, our research has the following different characteristics compared with previous studies: 1) covering a variety of allergic diseases, 2) exploring both aeroallergens and food allergens simultaneously, 3) including a large set of data from seven regions of mainland China, and 4) using an internationally recognized method of sIgE testing, ImmunoCAP, to detect sensitization. The above advantages may help us obtain more accurate and reliable results and conclusions.

In this paper, we explored the prevalence and patterns of sensitization to the four most common food allergens and five aeroallergens among patients with allergic symptoms in all the seven geographic regions of mainland China. The influences of seasonal and age variations on prevalence were also investigated. Furthermore, we specifically explored the factors that influenced these variations. Allergen sensitization patterns in different population demographics may contribute to improving the diagnosis and prevention of allergic diseases and then reducing economic losses.

\section{Methods}

\section{Study population}

This was a multicenter study covering 44156 patients in 52 cities (from 26 provinces, 7 geographical regions) of mainland China from July 2015 to June 2018. The patients suffered from clinical symptoms of suspected allergic diseases, and serum allergen sIgE levels were detected. The suspected allergic diseases included allergic rhinitis (such as runny nose, sneezing, itching or nasal obstruction), skin allergy (such as rashes, wheal, eczema, or urticaria), and allergic asthma (such as wheezing, dyspnea, and/or cough not due to common cold). Patients with parasitic infections, immunodeficiency or under specific immunotherapy were excluded. The analyzed data covered the information on the medical diagnosis, demographic data, and sIgE levels for nine allergens. This study was approved by the ethics committee of the First Affiliated Hospital of Guangzhou Medical University (Approval number: GYFYY-2017-18).

\section{Allergen-specific IgE detection}

All patient serum sIgE samples were collected and tested by a certified third-party laboratory service provider, KingMed Diagnostics, with uniform and standardized procedures.

A full-automated in vitro allergen detector, the ImmunoCAP 1000 system (Thermo Fisher Scientific Inc., California, USA), was used to detect allergen-specific sIgE in the sera, as described elsewhere ${ }^{9,11}$. The sIgE levels for nine categories of allergens (ImmunoCAP number, species source) were evaluated in this study, including those for the house dust mite (d1: house dust mite;Dermatophagoides pteronyssinus ), German cockroach (i6;Blatella germanica), tree pollen mix (tx4: Quercus alba, Ulmus americana, Platanus acerifolia, Salix caprea,Populus deltoides ), mold mix (mx1: Penicillium chrysogenum, Cladosporium herbarum, Aspergillus fumigatus, Alternaria alternata), dog dander (e5), egg whites (f1), cow's milk (f2), crab (f23), and shrimp (f24). Positive reactivity was defined as an sIgE level [?] $0.35 \mathrm{kUA} / \mathrm{L}$ (class 1 or above). According to the absolute sIgE levels, the reactivity was categorized quantitatively into six classes: class 1 ([?] 0.35 to $<0.70 \mathrm{kUA} / \mathrm{L}$ ), class 2 ([?] 0.70 to $<3.50 \mathrm{kUA} / \mathrm{L}$ ), class 3 ([?] 3.50 to $<17.50 \mathrm{kUA} / \mathrm{L}$ ), 
class 4 ([?] 17.50 to $<50.00 \mathrm{kUA} / \mathrm{L})$, class 5 ([?] 50.00 to $<100.00 \mathrm{kUA} / \mathrm{L})$, and class 6 ([?] $100.00 \mathrm{kUA} / \mathrm{L})$ 9,11 .

\section{Geographical regions of mainland China}

Based on natural and socioeconomic situations, the mainland China contains seven geographic regions, EC: East China, CC: Central China, NC: North China, NEC: Northeast China, NWC: Northwest China, SC: South China and SWC: Southwest China ${ }^{12}$.

\section{Statistical analysis}

The prevalence of positive sIgE tests for allergens was calculated as a proportion. Sex, age, region and month groups were analyzed as categorical variables. The differences in the rates of sensitization between the variables were analyzed using the chi-square test and Fisher's exact test. All data were transferred to and analyzed in R studio 3.6.2.

\section{Results}

\section{The overall prevalence of $\mathrm{SIgE}$ responses to allergens}

The overall prevalence of positive sIgE responses to the 9 allergens across mainland China from highest to lowest was $33.74 \%$ for house dust mites, $24.5 \%$ for cockroaches, $19.97 \%$ for shrimp, $17.31 \%$ for crab, $11.62 \%$ for cow's milk, $10.92 \%$ for egg whites, $9.35 \%$ for tree pollen mix, $4.02 \%$ for dog dander and $3.92 \%$ for mold mix. The results in Table 1 show that the concentrations of sIgE to all allergens were mainly lower than $3.50 \mathrm{kUA} / \mathrm{L}$ (class 1 and class 2). The higher the sIgE level was for an allergen, the lower the likelihood of classification from class 3 to class 6 .

\section{SIgE reactivities to allergens in male and female subjects}

The results from Table 1 reflect that there was a significant difference $(\mathrm{P}<0.001)$ between male and female subjects in the prevalence of all 9 allergens. Furthermore, the prevalence of sensitization was higher among men than women for all allergens.

\section{SIgE reactivities to allergens in patients from different age groups}

In this paper, we classified the age into 10 groups as shown in Figure 1. Chi-square tests were conducted to test the differences among age groups for each allergen. The analyzed results showed significant differences $(\mathrm{P}<0.05$ for tree pollen mix and $\mathrm{P}<0.001$ for the other eight allergens) among age groups for all allergens. Furthermore, the prevalence of sIgE response to egg whites and cow's milk had very similar patterns among age groups. The positive rates decreased as age increased. For crab, shrimp, house dust mites, dog dander and German cockroaches, the positive rates are higher in the middle age groups and lower in the upper and lower age extremes. The troughs in prevalence of sensitization to these allergens were all located in age group 0-3; however, it is the age group that has the highest prevalence for egg whites and cow's milk. The prevalence of sIgE response to the mold mix was lowest in patients younger than 3 years old, and the prevalence in other age groups was relatively stable.

$\mathrm{sIgE}$ reactivities to allergens in patients from different age groups among male and female subjects

Binary logistic regression was used to analyze the odds ratio (OR) of the male to female subjects in each age group for positive reactions to allergens. In Figure 2, for house dust mites, German cockroach, shrimp and mold mix, the ORs were larger than 1.0 for all age groups, and most of the p values were less than 0.05 . The odds of male subjects exhibiting sensitization in the age ranges $9^{\sim} 15$ years old for three pollen mix, $6^{\sim} 12$ years old and 40 60 years old for egg whites, $9^{\sim} 12$ and 15 18 years old for cow's milk, $12^{\sim} 18$ years old for dog dander and $15^{\sim} 18$ years old for crab were higher than those for female subjects; however, the differences were not statistically significant $(\mathrm{P}>0.05)$. Furthermore, the odds of male subjects in the total population exhibiting sensitization were higher than of female subjects for all nine allergens. The results were consistent with Table 1. 


\section{Prevalence of sIgE response to allergens in different regions of mainland China}

Table 2 displayed detailed data of each allergen in seven regions of mainland China. The chi-square test was applied to test the difference in the prevalence of sensitization to allergens among seven regions. The results showed a significant difference in the prevalence among regions for all 9 allergens except for the mold mix. To show the prevalence results integrated with the map of China, we generated a heatmap of the prevalence of the sIgE response to allergens in different regions (Figure 3). From the figure, we can obtain the distribution of the prevalence of the sIgE response to allergens in different regions of mainland China.

The prevalence patterns of the egg whites and milk in Central China (16.91\% and $17.55 \%$, respectively) and East China (14.67\% and $15.99 \%$, respectively) and South China (12.23\% and $15.16 \%$, respectively) were higher than those in Southwest China, North China and Northeast China (all lower than 9.68\%), which means that patients living in eastern, coastal and or southern areas were more sensitive to egg whites and cow's milk. For crab and shrimp, the prevalence of both sensitization in Southwest China $(19.14 \%$ and $22.69 \%$, respectively) and South China (17.5\% and $19.3 \%$, respectively) was higher than that in the northern regions (North China and Northeast China, which were both lower by $7.19 \%$ ). House dust mites were the allergen with the highest positive rate in all 7 regions, with the highest in South China (40.79\%), followed by East China $(36.00 \%)$ and Southwest China $(32.22 \%)$, and the lowest positive rates were found in Northeast China (11.21\%). Allergies to German cockroaches had a higher prevalence in southern regions (Southwest China $(29.25 \%)$, South China $(21.67 \%)$ and East China (20.85\%)) than in northern regions (North China $(7.32 \%)$ and Northeast China (5.97\%)). The prevalence of sIgE responses to dog dander were the highest in North China (8.72\%), and the prevalence in the southern regions $\left(3.18^{\sim} 4.14 \%\right)$ was very close to each other.

\section{SIgE reactivities to allergens in patients from different months}

Figure 4 displayed the prevalence pattern of allergens in a year month. Prevalence of dog dander and mold mix in a year month is very stable. The prevalence of other allergens fluctuates from January to December. Peaks of tree pollen mix are located in April and October when the prevalence is much higher than in other months. The prevalence of German cockroach and house dust mite sensitization varied obviously during the 12 months, but it did not vary as much as sensitization to the tree pollen mix. For German cockroaches, the peak was in June to August, when the prevalence was as high as approximately $28 \%$, and the trough occurred in October when the prevalence was as low as $18 \%$. The prevalence of other months fluctuated between $20 \%$ and $25.8 \%$. The prevalence of house dust mite sensitization increased starting in April and rises to peak in July and then gradually decreases and tends to balance from October. The prevalence of food allergen sensitization also fluctuated among months. The prevalence of crab and shrimp sensitization was somewhat similar to that of house dust mites. Their prevalence patterns increased from May and formed a large and smooth peak in June, July and August, decreased in September and tended to stabilize starting in October. Fluctuations in the prevalence of egg whites and cow's milk sensitization were smaller than those in crab and shrimp, but peaks existed. The peaks for cow's milk and egg whites were located in May and June, respectively.

\section{Discussion}

This was the first study to investigate the difference in the prevalence and patterns of allergen sensitization in patients with allergic symptoms from all the seven geographic regions of mainland China. Based on this large study, the most common allergen for patients with allergic diseases in mainland China was house dust mites. The results were consistent with those of previous studies ${ }^{6}$. Studies have also reported that house dust mites were the most common aeroallergen in many Asian countries ${ }^{7,}{ }^{13}$. Another study also reported a high prevalence of $90 \%$ in Taiwan for house dust mite allergies. This is quite different from other continents of the world. For example, cat and dog allergies are the most common allergies in Europe and the United States ${ }^{7,14}$, while in Africa, the most common allergies are cat and cockroach. The differences may be caused by lifestyle factors, socioeconomic factors and genetic predispositions ${ }^{15}$. In European and Western countries, people usually dry laundry with clothes dryers, which is helpful for killing house dust mites. Although the United States and China have similar longitudes and latitudes, which means that they may have similar 
climates, the populations of these regions have different genetic makeups. Therefore, genetic predisposition may also explain the difference in the prevalence of house dust mites ${ }^{13}$.

The statistical tests showed a significant difference in the prevalence of allergens among different regions except for mold mix. The prevalence of house dust mite sensitization had obvious regional characteristics. The further south and the more coastal an area was, the higher the prevalence. Humility and temperature are the primary two determinant factors that affect dust mite reproduction and growth ${ }^{16}$. It is easy for them to grow in warm and humility places ${ }^{8}$. A study ${ }^{16}$ concluded that few house dust mites were found in houses with ample sunshine. Studies also found that long lint-covered and handmade carpets, wool and synthetic blankets, and synthetic quilts could result in more mites ${ }^{17}$. Studies ${ }^{16,}{ }^{17}$ also found that the age of homes and mattresses are also positive factors affecting the number of house dust mites. Regions in South and coastal are in have subtropical and tropical climates with higher temperature and relative humidity than other regions. The higher indoor number of house dust mites in southern coastal region than those from North region may also can explain the higher prevalence of house dust mite sensitization in the southern regions than in the northern and eastern regions. Furthermore, people in the north are provided with heating for at least 5 months a year, which results in low indoor humidity. Therefore, this lifestyle can also be the reason for the lower prevalence in the north. In regions other than northern regions, which do not have heating supplies, people usually need long and thick carpets, blankets and quilts to keep warm indoors, all of which contribute to the proliferation of house dust mites. The buildings in the cities in the northern regions in our study had the characteristics of fewer floors and larger spacing, which enables a greater supply of sunlight for the indoor rooms, resulting in fewer house dust mites in the north.

German cockroaches were the second most common allergen affecting allergic patients in mainland China, with a prevalence of $24.5 \%$. Previous studies reported positivity rates of $11.5 \%-18.7 \% 6,18$ for SPT and $20.9-26.5 \%^{9}$ for sIgE. Cockroaches have been reported to be one of the most common indoor allergens worldwide ${ }^{19}$. Cockroach sensitization has been reported as $30 \%$ in Africa, 30\% in India, and 6-29\% in European countries. The high prevalence may be caused by immune regulation, genetic determinants ${ }^{20}$ and cross-reactivity between cockroaches and house dust mites ${ }^{18}$. The prevalence in Southwest and Southern coast China was higher than those in the East and North China. However, Southwest China had higher prevalence than Southcoast. This was different from the prevalence pattern of house dust mite sensitization. The climate in the south may be more comfortable for cockroach growth than that in the north. However, compared with American cockroaches, German cockroaches are commonly found in dry and cold conditions ${ }^{21}$, which may be the reason for the higher prevalence in Southwest than in Southcoast China. Southcoast is more humid and hotter than west.

The prevalence of tree pollen mix sensitization varied among regions. This may be attributed to different plant species in different $\operatorname{areas}^{22}$.

Among the four food allergens in our study, their prevalence fell into the range of $10 \%-20 \%$. The prevalence of cow's milk and egg whites in North China was higher than those in other regions. The difference may be caused by the low ethnicity-dependent genetic polymorphisms in vitamin D-binding protein, which evoke differential effects on vitamin D bioavailability. On the other hand, dietary patterns may also be the reason for variation in the prevalence of food allergens in different regions. Studies have concluded that infant diets with high levels of fruits, vegetables, and home-prepared foods are associated with fewer food allergies ${ }^{23}$. People in provinces such as Hubei, Hunan, and Jiangxi eat more peppers than people in other regions, which may lead to high sensitization to eggs. The high prevalence of cow's milk in East China may be caused by a family history of food allergies and atopy ${ }^{24}$. However, further evidence is required. Geographical variations in the patterns of aeroallergens also influence food allergy distributions where cross-reactivity exists between aeroallergen and food allergen components ${ }^{25,26}$. In our study, the prevalence patterns of crab and shrimp sensitization in all regions were quite similar to that of cockroaches, which may be caused by cross-reactivity. Furthermore, the higher prevalence may also have been because of high exposure to crabs and shrimp because people living near the coast were more likely to eat seafood. Different regions have different allergen sensitization patterns, which will provide a favorable basis for local allergen diagnosis and 
treatment.

Sex-based differences in the prevalence of allergies have long been recognized. However, conclusions about this topic are inconsistent among questionnaire studies and the detection of specific IgE antibodies or skin prick tests ${ }^{27}$. In our study, the prevalence of all nine common allergens was significantly higher in men than in women. This suggests that being male is one of the risk factors for allergen sensitization. The results may be connected to sexual hormones and differences in the lifestyles, such as diet, sports, doctors and hormonal medications ${ }^{28}$. Further studies need to be conducted.

Age had an influence on the prevalence of sensitization for all allergens except the tree pollen mix. However, a previous study found that in young and middle-aged patients with rhinitis and/or asthma, the prevalence of pollen varied in different age groups ${ }^{8}$. Our results were different from others, possibly because of the small sample size. The patterns for the prevalence of egg white and cow's milk sensitization both typically presented a falling curve with increasing age. The prevalence of egg whites and cow's milk among individuals younger than 6 years old was obviously much higher than that of milk in individuals older than 6 years old. The patterns were quite similar to the findings in a previous study ${ }^{8}$. Egg whites and cow's milk were the two major food sources of sensitization for younger children, who have immature immune systems. The results also showed that the prevalence patterns of crabs and shrimp were higher in the middle-aged groups than in the other groups. This may be attributed to different lifestyles, such as high exposure in crabs and shrimp, and may also be regarded as cross-reactivity ${ }^{8}$. The identification of major allergens in different age groups can help to improve the pertinence and accuracy of allergen detection for clinical diagnosis, which can reduce the burden of medical expenses for patients.

The peaks of German cockroach and house dust mite sensitization prevalence were both located in summer, which may be explained by the fact that house dust mites and cockroaches grow more easily and are more common in warm and humid conditions. The prevalence of sensitization to the tree pollen mix was significantly higher in April and October, which was consistent with the flowering seasons of most plants ${ }^{22}$. The prevalence of egg white and cow's milk sensitization was higher in spring, and crab and shrimp sensitization in summer may be influenced by seasonal differences in UVB exposure ${ }^{29}$. There were differences in the distributions of allergen sensitizations in different seasons, which can be used for prospective prevention and treatment of allergic diseases.

\section{Conclusion}

This large population-based study of allergic patients in mainland China found that the prevalence of allergens displayed obvious and distinctive patterns among regions, age groups and seasons. Based on previous studies, the reasons for the above results may include lifestyle factors, socioeconomic factors, genetic predispositions, climate, sexual hormones, cross-reactivity and so on. The factors were so complicated that deeper studies are needed. Our article may help clinicians find effective individualized treatments for unique patient groups. Researchers may obtain some instructions for deeper studies on the epidemiology of allergic diseases.

\section{Reference}

1. Zeng GQ, Luo JY, Huang HM, et al. Food allergy and related risk factors in 2540 preschool children: an epidemiological survey in Guangdong Province, southern China. World journal of pediatrics : WJP . Aug 2015;11(3):219-25. doi:10.1007/s12519-015-0030-6

2. Kim DH, Park YS, Jang HJ, Kim JH, Lim DH. Prevalence and allergen of allergic rhinitis in Korean children. American journal of rhinology \& allergy . May 2016;30(3):72-8. doi:10.2500/ajra.2013.27.4317

3. Hu Y, Chen J, Li H. Comparison of food allergy prevalence among Chinese infants in Chongqing, 2009 versus 1999. Pediatrics international : official journal of the Japan Pediatric Society . Oct 2010;52(5):820-4. doi:10.1111/j.1442-200X.2010.03166.x

4. Ebert CS, Jr., Pillsbury HC, III. Epidemiology of\&\#xa0;Allergy.Otolaryngologic Clinics of North America . 2011;44(3):537-548. doi:10.1016/j.otc.2011.03.001 
5. Lin J, Wang W, Chen P, et al. Prevalence and risk factors of asthma in mainland China: The CARE study. Respiratory medicine. Apr 2018;137:48-54. doi:10.1016/j.rmed.2018.02.010

6. Li J, Sun B, Huang Y, et al. A multicentre study assessing the prevalence of sensitizations in patients with asthma and/or rhinitis in China. Allergy . Jul 2009;64(7):1083-92. doi:10.1111/j.1398-9995.2009.01967.x

7. Tham EH, Lee AJ, Bever HV. Aeroallergen sensitization and allergic disease phenotypes in Asia. Asian Pacific journal of allergy and immunology . Sep 2016;34(3):181-189. doi:10.12932/ap0770

8. Sun BQ, Zheng PY, Zhang XW, Huang HM, Chen DH, Zeng GQ. Prevalence of allergen sensitization among patients with allergic diseases in Guangzhou, Southern China: a four-year observational study.Multidisciplinary respiratory medicine . Jan 15 2014;9(1):2. doi:10.1186/2049-6958-9-2

9. Zeng G, Luo W, Wu Z, et al. A cross-sectional observational study on allergen-specific IgE positivity in a southeast coastal versus a southwest inland region of China. Scientific reports. Aug 30 2017;7(1):9593. doi:10.1038/s41598-017-10109-3

10. O'Driscoll BR, Powell G, Chew F, et al. Comparison of skin prick tests with specific serum immunoglobulin $\mathrm{E}$ in the diagnosis of fungal sensitization in patients with severe asthma. Clinical and experimental allergy : journal of the British Society for Allergy and Clinical Immunology . Nov 2009;39(11):1677-83. doi:10.1111/j.1365-2222.2009.03339.x

11. Luo W, Huang H, Zheng $\mathrm{P}$, et al. Major grass pollen allergens and components detected in a southern Chinese cohort of patients with allergic rhinitis and/or asthma. Molecular immunology . Oct 2016;78:105112. doi:10.1016/j.molimm.2016.08.013

12. Ma C, Yang J, Chen F, et al. Assessing Heavy Industrial Heat Source Distribution in China Using Real-Time VIIRS Active Fire/Hotspot Data.Sustainability . 11/26 2018;10:4419. doi:10.3390/su10124419

13. Dey D, Saha GK, Podder S. A review of house dust mite allergy in India. Experimental \& applied acarology . May 2019;78(1):1-14. doi:10.1007/s10493-019-00366-4

14. Dávila I, Domínguez-Ortega J, Navarro-Pulido A, et al. Consensus document on dog and cat allergy. Allergy . Jun 2018;73(6):1206-1222. doi:10.1111/all.13391

15. Johnston JD, Barney TP, Crandall JH, et al. Prevalence of house dust mite allergens in low-income homes with evaporative coolers in a semiarid climate. Archives of environmental $\mathbb{E}$ occupational health. Jan 2 2018;73(1):38-41. doi:10.1080/19338244.2017.1282846

16. Ziyaei T, Berenji F, Jabbari-Azad F, Fata A, Jarahi L, Fereidouni M. House Dust Mite Prevalence in the House of Patients with Atopic Dermatitis in Mashhad, Iran. Journal of arthropod-borne diseases . Jun 2017;11(2):309-314.

17. Mihrshahi S, Marks G, Vanlaar C, Tovey E, Peat J. Predictors of high house dust mite allergen concentrations in residential homes in Sydney.Allergy . Feb 2002;57(2):137-42. doi:10.1034/j.1398-9995.2002.5720999.x

18. Sun BQ, Lai XX, Gjesing B, Spangfort MD, Zhong NS. Prevalence of sensitivity to cockroach allergens and IgE cross-reactivity between cockroach and house dust mite allergens in Chinese patients with allergic rhinitis and asthma. Chinese medical journal . Dec 2010;123(24):3540-4.

19. Sohn MH, Kim KE. The cockroach and allergic diseases. Allergy, asthma 86 immunology research . Sep 2012;4(5):264-9. doi:10.4168/aair.2012.4.5.264

20. Gao P. Sensitization to cockroach allergen: immune regulation and genetic determinants. Clinical $\mathscr{E}$ developmental immunology . 2012;2012:563760. doi:10.1155/2012/563760

21. Ozdemir O. Cockroach Allergy, Respiratory Allergic Diseases and Its Immunotherapy. International Journal of Immunology and Immunotherapy . 12/31 2014;1doi:10.23937/2378-3672/1410002 
22. Liu Z-G, Song J-J, Kong X-L. A Study on Pollen Allergens in China.Biomedical and Environmental Sciences . 2010/08/01/2010;23(4):319-322. doi:https://doi.org/10.1016/S0895-3988(10)60070-0

23. Grimshaw KE, Maskell J, Oliver EM, et al. Diet and food allergy development during infancy: birth cohort study findings using prospective food diary data. The Journal of allergy and clinical immunology . Feb 2014;133(2):511-9. doi:10.1016/j.jaci.2013.05.035

24. Yang M, Tan M, Wu J, et al. Prevalence, Characteristics, and Outcome of Cow's Milk Protein Allergy in Chinese Infants: A Population-Based Survey. JPEN Journal of parenteral and enteral nutrition . Aug 2019;43(6):803-808. doi:10.1002/jpen.1472

25. Tham EH, Leung DYM. How Different Parts of the World Provide New Insights Into Food Allergy. Allergy, asthma $\mathcal{E}$ immunology research . Jul 2018;10(4):290-299. doi:10.4168/aair.2018.10.4.290

26. Biedermann T, Winther L, Till SJ, Panzner P, Knulst A, Valovirta E. Birch pollen allergy in Europe. Allergy . Jul 2019;74(7):1237-1248. doi:10.1111/all.13758

27. Chen W, Mempel M, Schober W, Behrendt H, Ring J. Gender difference, sex hormones, and immediate type hypersensitivity reactions.Allergy . Nov 2008;63(11):1418-27. doi:10.1111/j.1398-9995.2008.01880.x

28. Jensen-Jarolim E. Gender effects in allergology - Secondary publications and update. The World Allergy Organization journal . 2017;10(1):47. doi:10.1186/s40413-017-0178-8

29. Vassallo MF, Banerji A, Rudders SA, Clark S, Mullins RJ, Camargo CA, Jr. Season of birth and food allergy in children. Annals of allergy, asthma $\& 3$ immunology : official publication of the American College of Allergy, Asthma, \& Immunology. Apr 2010;104(4):307-13. doi:10.1016/j.anai.2010.01.019

Table 1. Overall prevalence of sIgE responses to 9 allergens and their proportion of each class as well as sIgE response to allergens in male and female subjects

\begin{tabular}{|c|c|c|c|c|c|c|c|c|c|}
\hline Allergens & Allergens & $\begin{array}{l}\text { House } \\
\text { dust } \\
\text { mite } \\
\text { (d1) }\end{array}$ & $\begin{array}{l}\text { German } \\
\text { cock- } \\
\text { roach } \\
\text { (i6) }\end{array}$ & $\begin{array}{l}\text { Tree } \\
\text { pollen } \\
\text { mix } \\
(\text { txy })\end{array}$ & $\begin{array}{l}\text { Mold } \\
\text { mix } \\
(m x 1)\end{array}$ & $\begin{array}{l}\text { Dog } \\
\text { dander } \\
\text { (e5) }\end{array}$ & $\begin{array}{l}\text { Egg } \\
\text { white } \\
\text { (f1) }\end{array}$ & $\begin{array}{l}\text { Cow's } \\
\text { milk } \\
\text { (f2) }\end{array}$ & $\begin{array}{l}\text { Crab } \\
\text { (f23) }\end{array}$ \\
\hline $\begin{array}{l}\text { Total } \\
\text { cases } \\
(\mathrm{N})\end{array}$ & $\begin{array}{l}\text { Total } \\
\text { cases } \\
(\mathrm{N})\end{array}$ & 31680 & 29343 & 9155 & 28746 & 31061 & 31109 & 31111 & 30830 \\
\hline $\begin{array}{l}\text { Positive } \\
\text { cases } \\
{[\mathrm{n}(\%)]}\end{array}$ & $\begin{array}{l}\text { Positive } \\
\text { cases } \\
{[\mathrm{n}(\%)]}\end{array}$ & $\begin{array}{l}10690 \\
(33.74)\end{array}$ & $\begin{array}{l}7189 \\
(24.5)\end{array}$ & $\begin{array}{l}856 \\
(9.35)\end{array}$ & $\begin{array}{l}1126 \\
(3.92)\end{array}$ & $\begin{array}{l}1249 \\
(4.02)\end{array}$ & $\begin{array}{l}3396 \\
(10.92)\end{array}$ & $\begin{array}{l}3616 \\
(11.62)\end{array}$ & $\begin{array}{l}5336 \\
(17.31)\end{array}$ \\
\hline \multirow{6}{*}{$\begin{array}{l}\text { proportion } \\
\text { of Classi- } \\
\text { fication } \\
{\left[n_{c}(\%)\right]}\end{array}$} & class 1 & $\begin{array}{l}2397 \\
(22.42)\end{array}$ & $\begin{array}{l}2232 \\
(31.05)\end{array}$ & $\begin{array}{l}471 \\
(55.02)\end{array}$ & $\begin{array}{l}533 \\
(47.34)\end{array}$ & $\begin{array}{l}711 \\
(56.93)\end{array}$ & $\begin{array}{l}1535 \\
(45.20)\end{array}$ & $\begin{array}{l}1411 \\
(39.02)\end{array}$ & $\begin{array}{l}1965 \\
(36.83)\end{array}$ \\
\hline & class 2 & $\begin{array}{l}3591 \\
(33.59)\end{array}$ & $\begin{array}{l}3571 \\
(49.67)\end{array}$ & $\begin{array}{l}282 \\
(32.94)\end{array}$ & $\begin{array}{l}408 \\
(36.23)\end{array}$ & $\begin{array}{l}424 \\
(33.95)\end{array}$ & $\begin{array}{l}1492 \\
(43.93)\end{array}$ & $\begin{array}{l}1708 \\
(47.23)\end{array}$ & $\begin{array}{l}2598 \\
(48.69)\end{array}$ \\
\hline & class 3 & $\begin{array}{l}2032 \\
(19.01)\end{array}$ & $\begin{array}{l}1240 \\
(17.25)\end{array}$ & $\begin{array}{l}64 \\
(7.48)\end{array}$ & $\begin{array}{l}149 \\
(13.23)\end{array}$ & $\begin{array}{l}89 \\
(7.13)\end{array}$ & $\begin{array}{l}308 \\
(9.07)\end{array}$ & $\begin{array}{l}436 \\
(12.06)\end{array}$ & $\begin{array}{l}670 \\
(12.56)\end{array}$ \\
\hline & class 4 & $\begin{array}{l}1197 \\
(11.20)\end{array}$ & $\begin{array}{l}134 \\
(1.86)\end{array}$ & $\begin{array}{l}17 \\
(1.99)\end{array}$ & $\begin{array}{l}29 \\
(2.58)\end{array}$ & $\begin{array}{l}17 \\
(1.36)\end{array}$ & $\begin{array}{l}49 \\
(1.44)\end{array}$ & $\begin{array}{l}46 \\
(1.27)\end{array}$ & $\begin{array}{l}80 \\
(1.50)\end{array}$ \\
\hline & class 5 & $\begin{array}{l}738 \\
(6.90)\end{array}$ & $\begin{array}{l}11 \\
(0.15)\end{array}$ & $\begin{array}{l}12 \\
(1.40)\end{array}$ & $\begin{array}{l}6 \\
(0.53)\end{array}$ & $\begin{array}{l}7 \\
(0.56)\end{array}$ & $\begin{array}{l}9 \\
(0.27)\end{array}$ & $\begin{array}{l}10 \\
(0.28)\end{array}$ & $\begin{array}{l}13 \\
(0.24)\end{array}$ \\
\hline & class 6 & $\begin{array}{l}735 \\
(6.88)\end{array}$ & $\begin{array}{l}1 \\
(0.01)\end{array}$ & $\begin{array}{l}10 \\
(1.17)\end{array}$ & $\begin{array}{l}1 \\
(0.09)\end{array}$ & $\begin{array}{l}1 \\
(0.08)\end{array}$ & $\begin{array}{l}3 \\
(0.09)\end{array}$ & $\begin{array}{l}5 \\
(0.14)\end{array}$ & $\begin{array}{l}10 \\
(0.19)\end{array}$ \\
\hline Male & $\mathrm{N}$ & 12084 & 10950 & 1866 & 10593 & 11742 & 11791 & 11815 & 11562 \\
\hline
\end{tabular}




\begin{tabular}{|c|c|c|c|c|c|c|c|c|c|}
\hline Allergens & Allergens & $\begin{array}{l}\text { House } \\
\text { dust } \\
\text { mite } \\
\text { (d1) }\end{array}$ & $\begin{array}{l}\text { German } \\
\text { cock- } \\
\text { roach } \\
\text { (i6) }\end{array}$ & $\begin{array}{l}\text { Tree } \\
\text { pollen } \\
\text { mix } \\
\left(t_{4}\right) \\
\end{array}$ & $\begin{array}{l}\text { Mold } \\
\text { mix } \\
(m x 1)\end{array}$ & $\begin{array}{l}\text { Dog } \\
\text { dander } \\
(e 5)\end{array}$ & $\begin{array}{l}\text { Egg } \\
\text { white } \\
\text { (f1) }\end{array}$ & $\begin{array}{l}\text { Cow's } \\
\text { milk } \\
\text { (f2) }\end{array}$ & $\begin{array}{l}\text { Crab } \\
\text { (f23) }\end{array}$ \\
\hline & n $(\%)$ & $\begin{array}{l}4547 \\
(37.63)\end{array}$ & $\begin{array}{l}3039 \\
(27.68)\end{array}$ & $\begin{array}{l}268 \\
(14.36)\end{array}$ & $\begin{array}{l}533 \\
(5.03)\end{array}$ & $\begin{array}{l}555 \\
(4.73)\end{array}$ & $\begin{array}{l}1732 \\
(14.69)\end{array}$ & $\begin{array}{l}1903 \\
(16.11)\end{array}$ & $\begin{array}{l}2310 \\
(19.98)\end{array}$ \\
\hline \multirow[t]{2}{*}{ female } & $\mathrm{N}$ & 14158 & 13011 & 2262 & 12707 & 13908 & 13907 & 13881 & 13800 \\
\hline & n $(\%)$ & $\begin{array}{l}4590 \\
(32.42)\end{array}$ & $\begin{array}{l}3180 \\
(24.44)\end{array}$ & $\begin{array}{l}245 \\
(10.83)\end{array}$ & $\begin{array}{l}420 \\
(3.31)\end{array}$ & $\begin{array}{l}496 \\
(3.57)\end{array}$ & $\begin{array}{l}1218 \\
(8.76)\end{array}$ & $\begin{array}{l}1136 \\
(8.18)\end{array}$ & $\begin{array}{l}2315 \\
(16.78)\end{array}$ \\
\hline $\mathrm{X}^{2}$ & $\mathrm{X}^{2}$ & 77.699 & 32.327 & 11.393 & 43.451 & 21.52 & 220.3 & 383.43 & 43.096 \\
\hline $\mathrm{P}$ & $\mathrm{P}$ & $\begin{array}{l}< \\
2.2 \mathrm{e}-16\end{array}$ & $\begin{array}{l}1.30 \mathrm{e}- \\
08\end{array}$ & 0.000737 & $\begin{array}{l}4.35 \mathrm{e}- \\
11\end{array}$ & $\begin{array}{l}3.50 \mathrm{e}- \\
06\end{array}$ & $\begin{array}{l}< \\
2.2 \mathrm{e}-16\end{array}$ & $\begin{array}{l}< \\
2.2 \mathrm{e}-16\end{array}$ & $\begin{array}{l}5.21 \mathrm{e}- \\
11\end{array}$ \\
\hline
\end{tabular}

Table 2. The prevalence and sample size of allergen sensitization in each region. ( $N$ : the total number of patients who were tested for the slgE to the allergen in the region, $n$ : the number of patients whose SIgE result was positive in that region.)

\begin{tabular}{|c|c|c|c|c|c|c|c|c|c|c|c|}
\hline & $\mathrm{SC}$ & $\mathrm{SC}$ & SWC & SWC & $\mathrm{CC}$ & $\mathrm{CC}$ & $\mathrm{EC}$ & $\mathrm{EC}$ & NEC & NEC & $\mathrm{NC}$ \\
\hline Allergens & $\mathrm{N}$ & $\mathrm{n}(\%)$ & $\mathrm{N}$ & n $(\%)$ & $\mathrm{N}$ & $\mathrm{n}(\%)$ & $\mathrm{N}$ & n $(\%)$ & $\mathrm{N}$ & $\mathrm{n}(\%)$ & $\mathrm{N}$ \\
\hline$d 1$ & 8834 & $3603(40.79)$ & 14632 & $4714(32.22)$ & 4334 & $1157(26.7)$ & 1161 & $418(36)$ & 464 & $52(11.21)$ & 218 \\
\hline$i 6$ & 7809 & $1692(21.67)$ & 14340 & $4195(29.25)$ & 4121 & $724(17.57)$ & 518 & $108(20.85)$ & 385 & $23(5.97)$ & 164 \\
\hline$t x 4$ & 2533 & $255(10.07)$ & 3640 & $319(8.76)$ & 1044 & $64(6.13)$ & 90 & $13(14.44)$ & 199 & $6(3.02)$ & 3 \\
\hline$m x 1$ & 7524 & $294(3.91)$ & 14046 & $552(3.93)$ & 4232 & $149(3.52)$ & 396 & $18(4.55)$ & 462 & $12(2.6)$ & 80 \\
\hline e5 & 8621 & $357(4.14)$ & 14662 & $606(4.13)$ & 4617 & $147(3.18)$ & 540 & $21(3.89)$ & 410 & $5(1.22)$ & 195 \\
\hline$f 1$ & 8920 & $1091(12.23)$ & 14562 & $1248(8.57)$ & 4389 & $742(16.91)$ & 593 & $87(14.67)$ & 438 & $42(9.59)$ & 186 \\
\hline f2 & 9012 & $1366(15.16)$ & 14521 & $1128(7.77)$ & 4401 & $770(17.5)$ & 594 & $95(15.99)$ & 381 & $27(7.09)$ & 185 \\
\hline f23 & 8670 & $1517(17.5)$ & 14460 & $2767(19.14)$ & 4332 & $543(12.53)$ & 590 & $82(13.9)$ & 559 & $25(4.47)$ & 198 \\
\hline f24 & 8615 & $1663(19.3)$ & 14458 & $3281(22.69)$ & 4329 & $624(14.41)$ & 596 & $97(16.28)$ & 411 & $30(7.3)$ & 153 \\
\hline
\end{tabular}

(d1: House dust mite, i6: German cockroach, tx4: Tree pollen mix, e5: Dog dander, mx1: mold mix, f1: Egg whites, f2: Cow's milk, f23: Crab, f24: Shrimp; EC: East China, CC: Central China, NC: North China, NEC: Northeast China, NWC: Northwest China, SC: South China, SWC: Southwest China) 


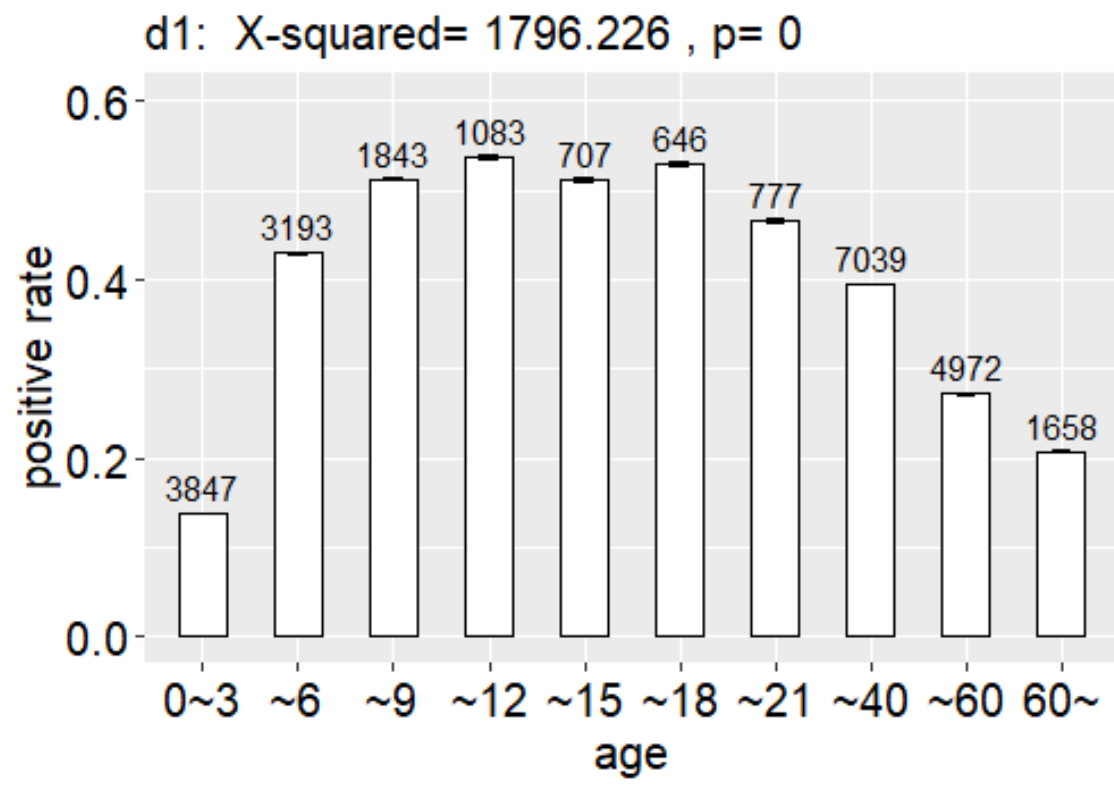

i6: $X$-squared $=1468.888, p=0$

$0.6^{-}$

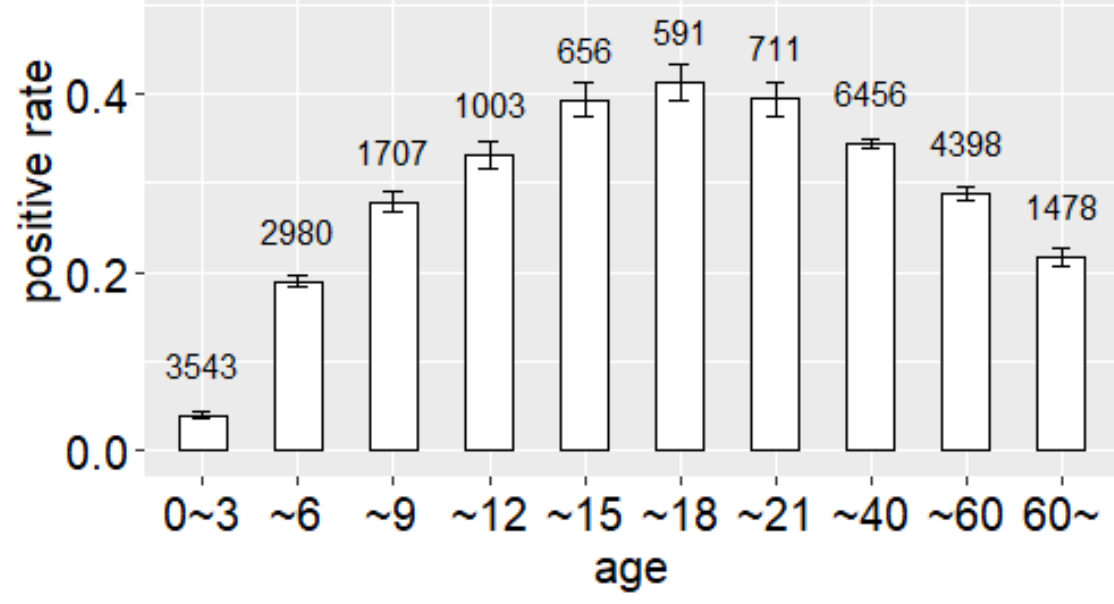



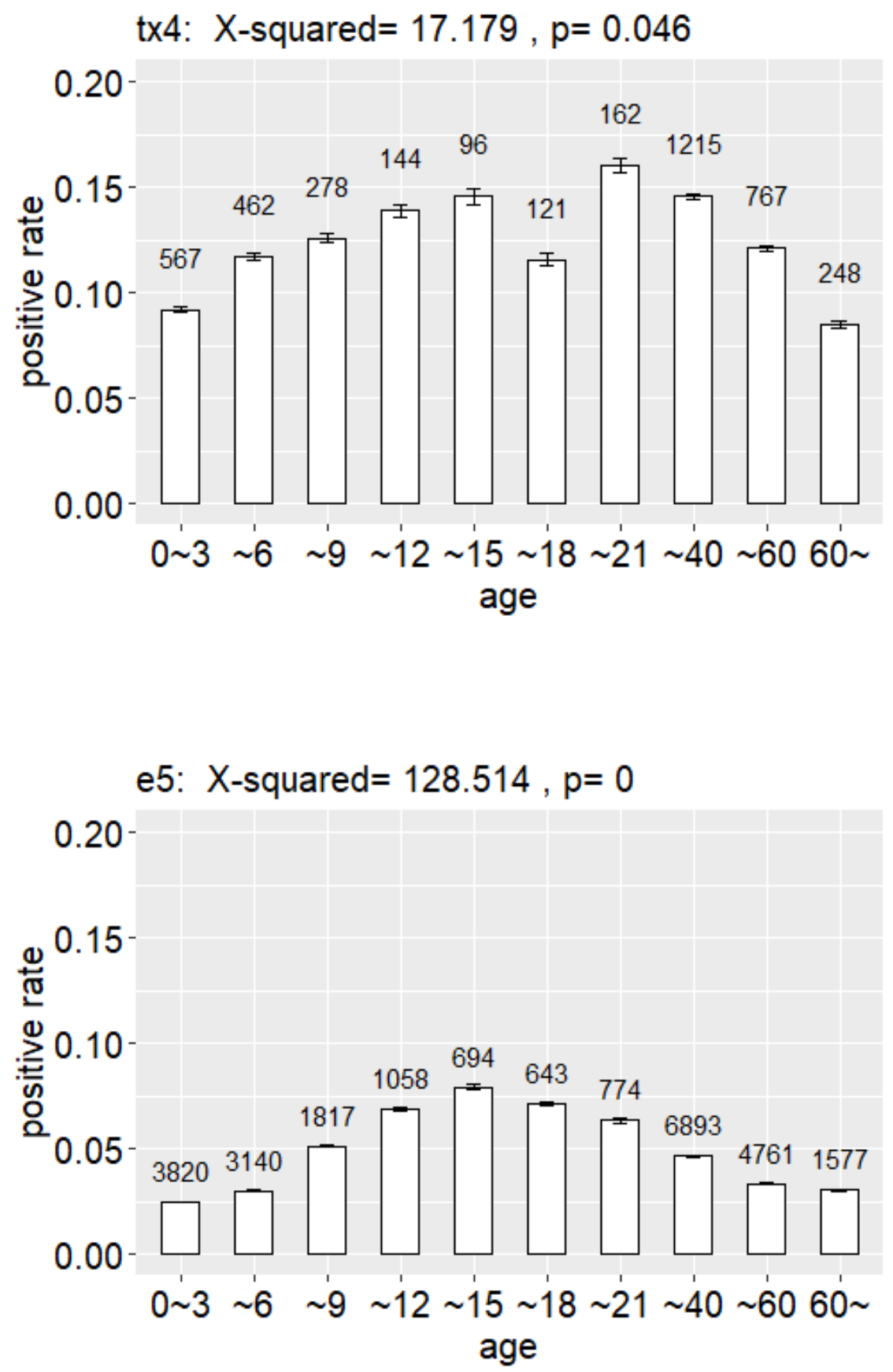

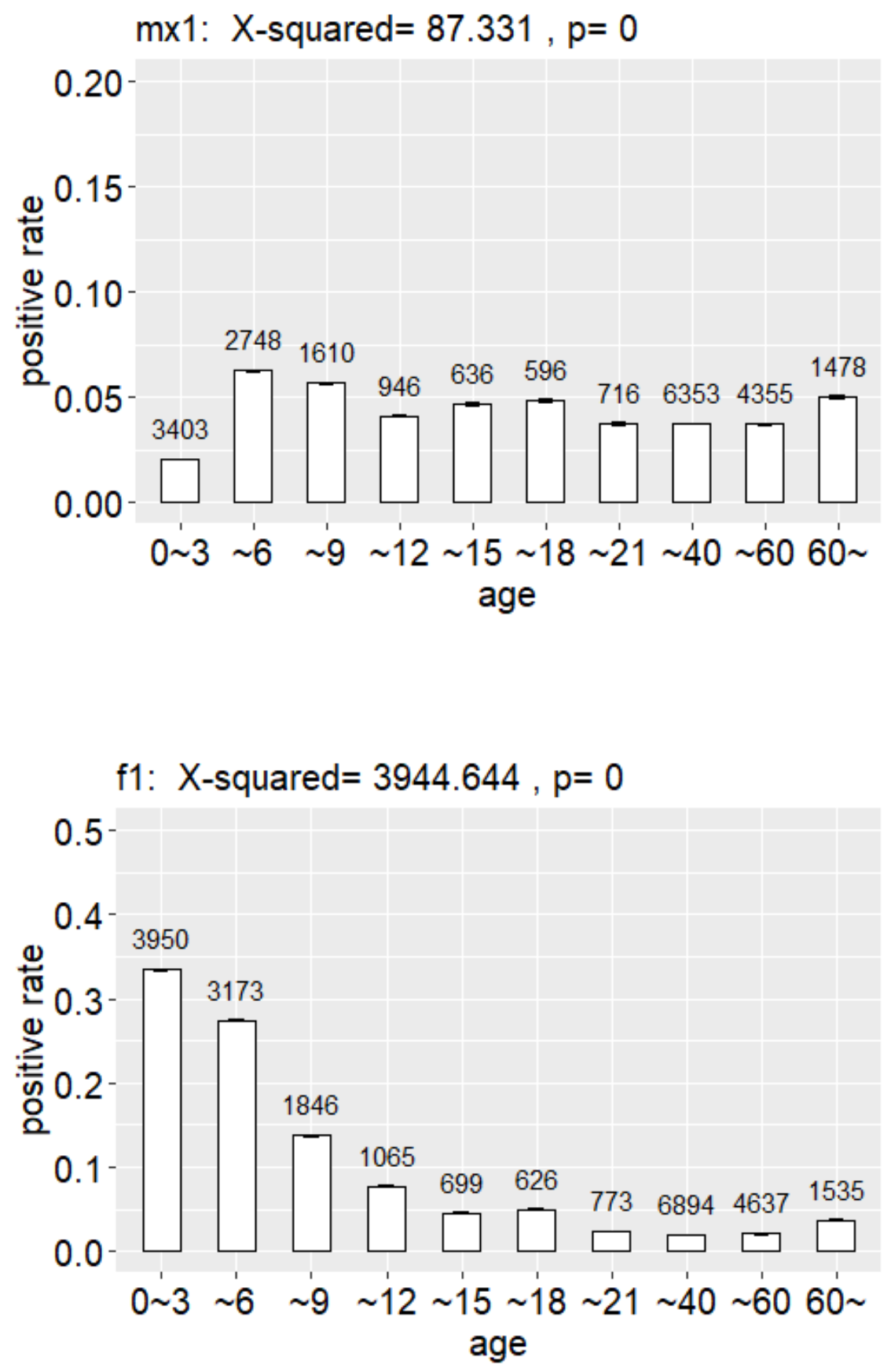

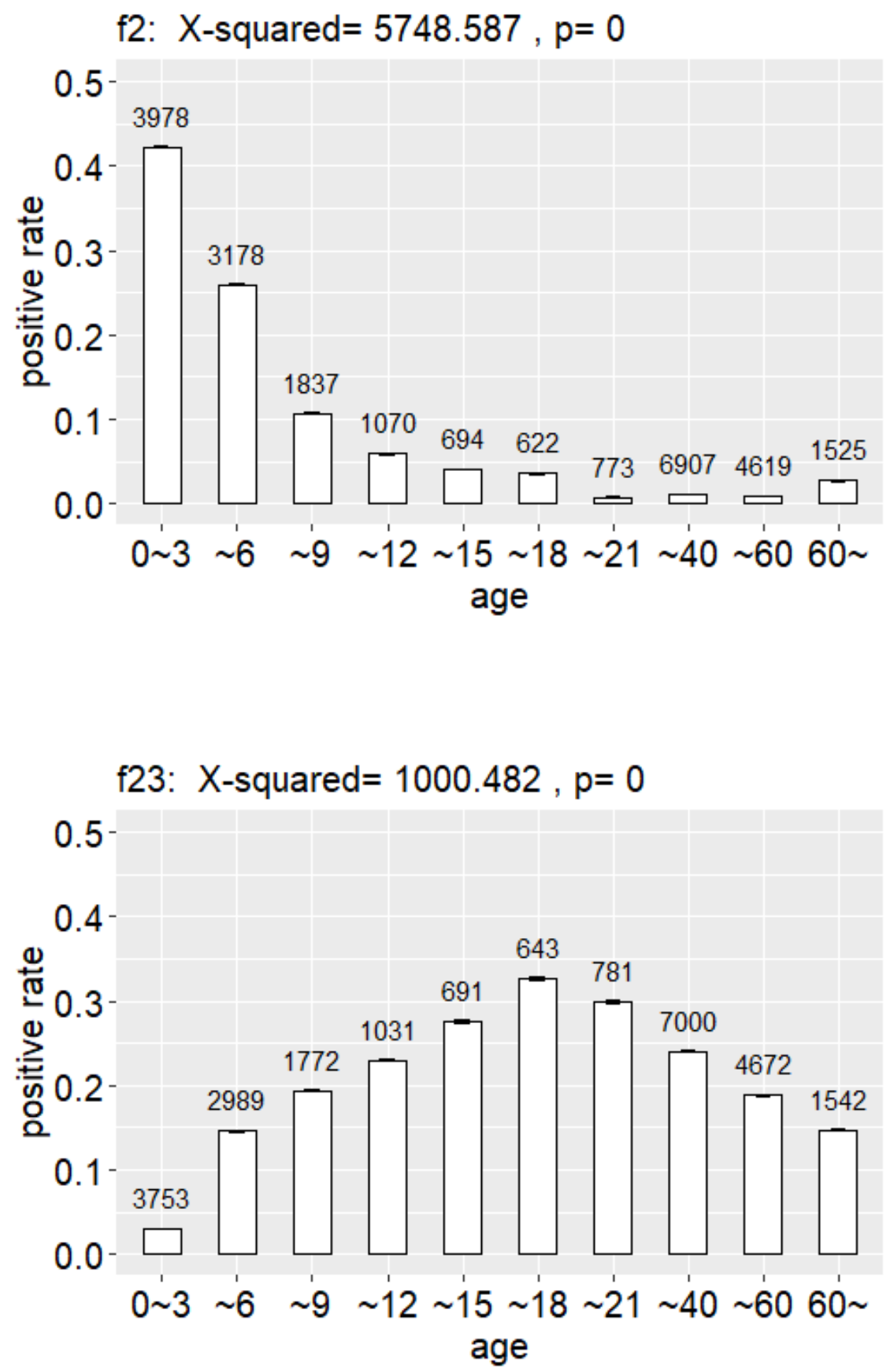


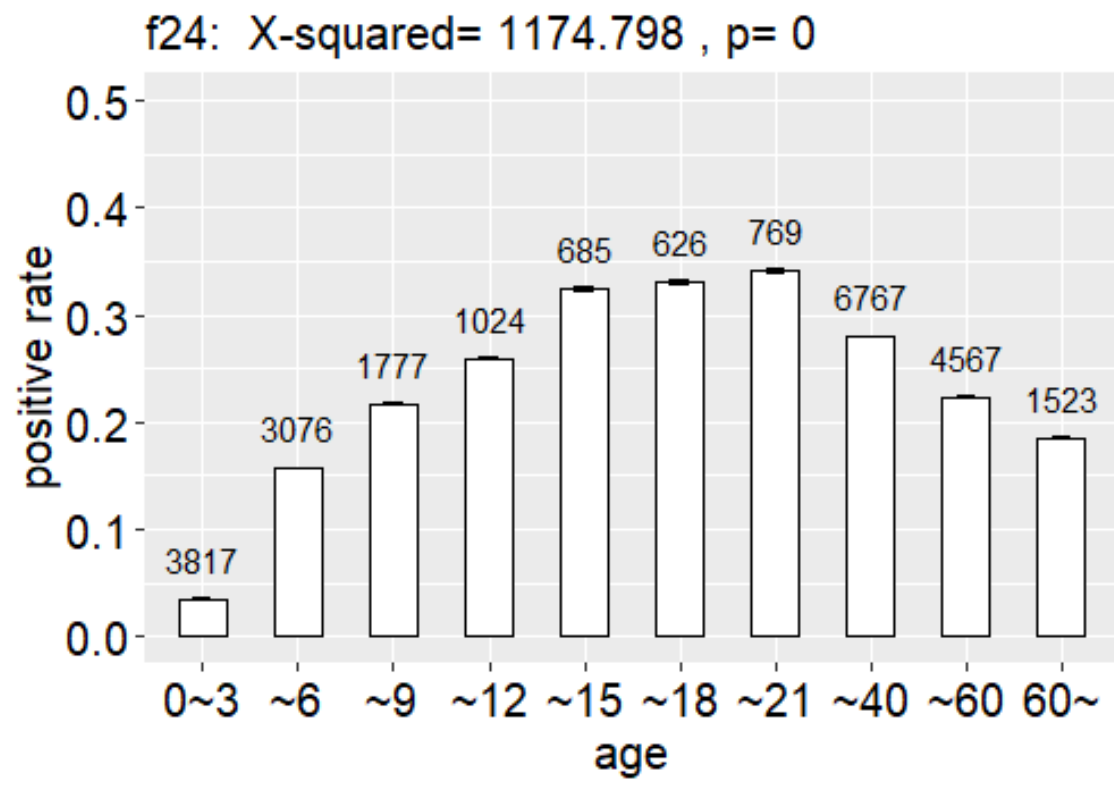

Figure 1. Positive rate of SIgE reactivity to allergens in different age groups. (The total number of each case is labeled above the bars, and the X-squared and $p$ values are also shown above the plots. d1: House dust mite, i6: German cockroach, tx4: Tree pollen mix, e5: Dog dander, mx1: Mold mix, f1: Egg white, f2: Cow's milk, f23: Crab, f24: Shrimp)

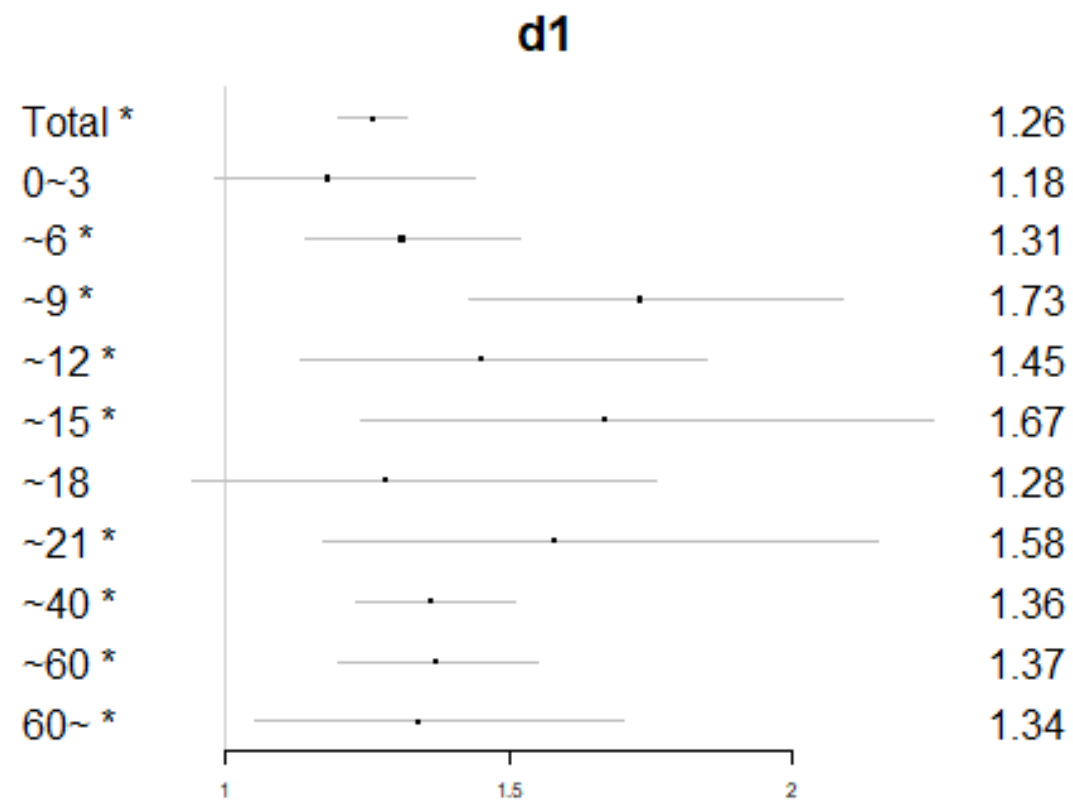


i6

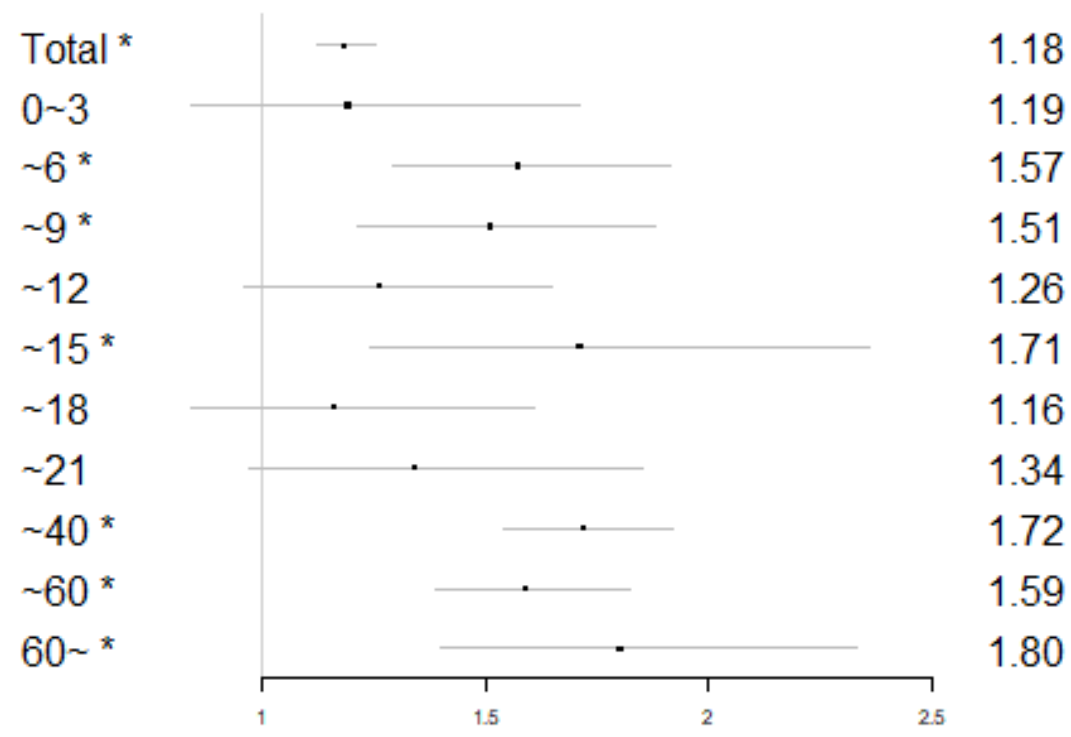

tx4

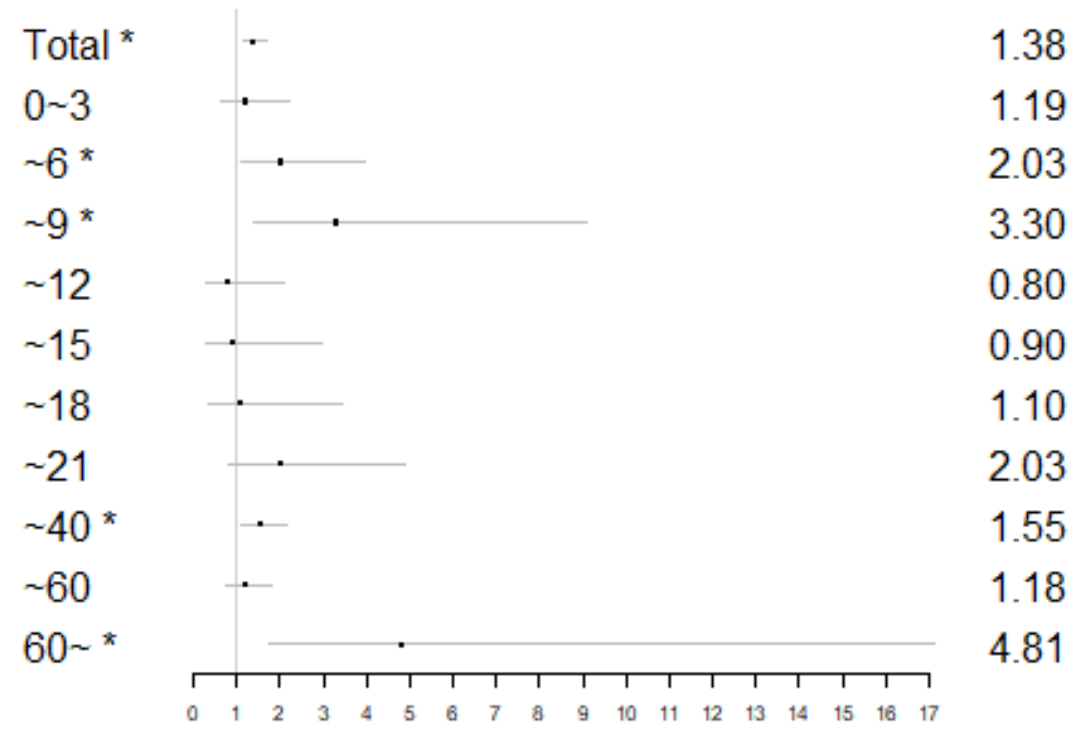




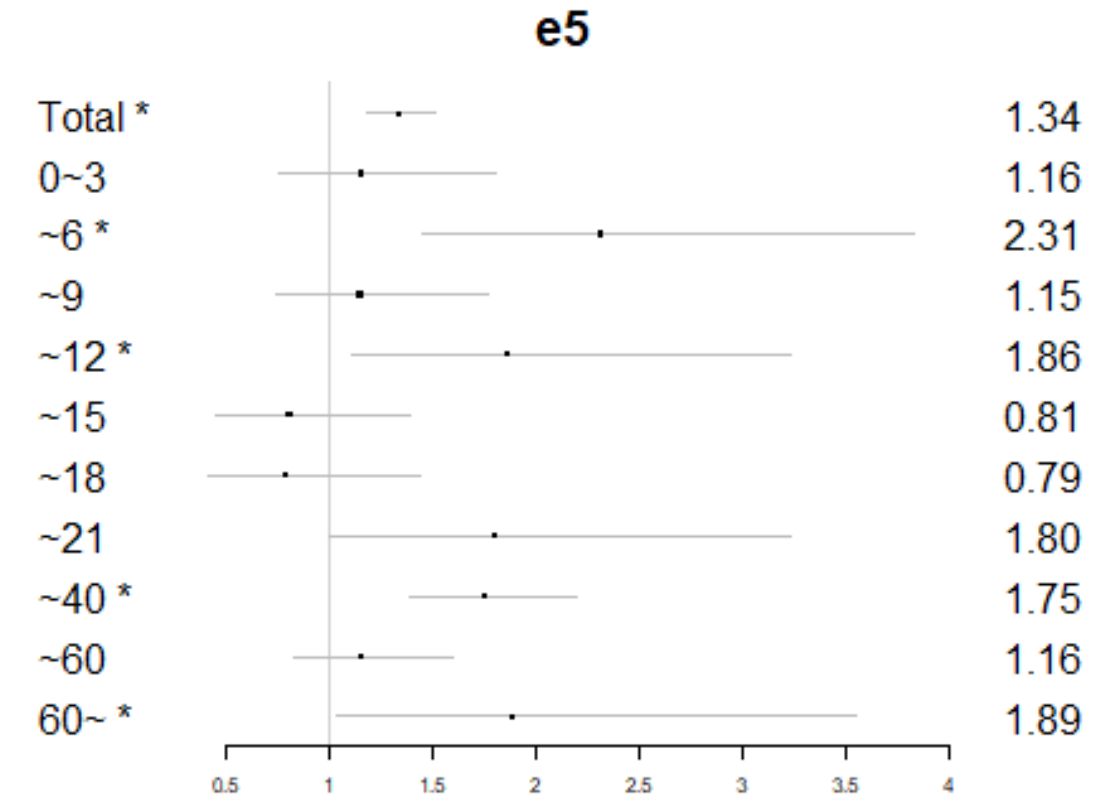

$\mathrm{mx1}$

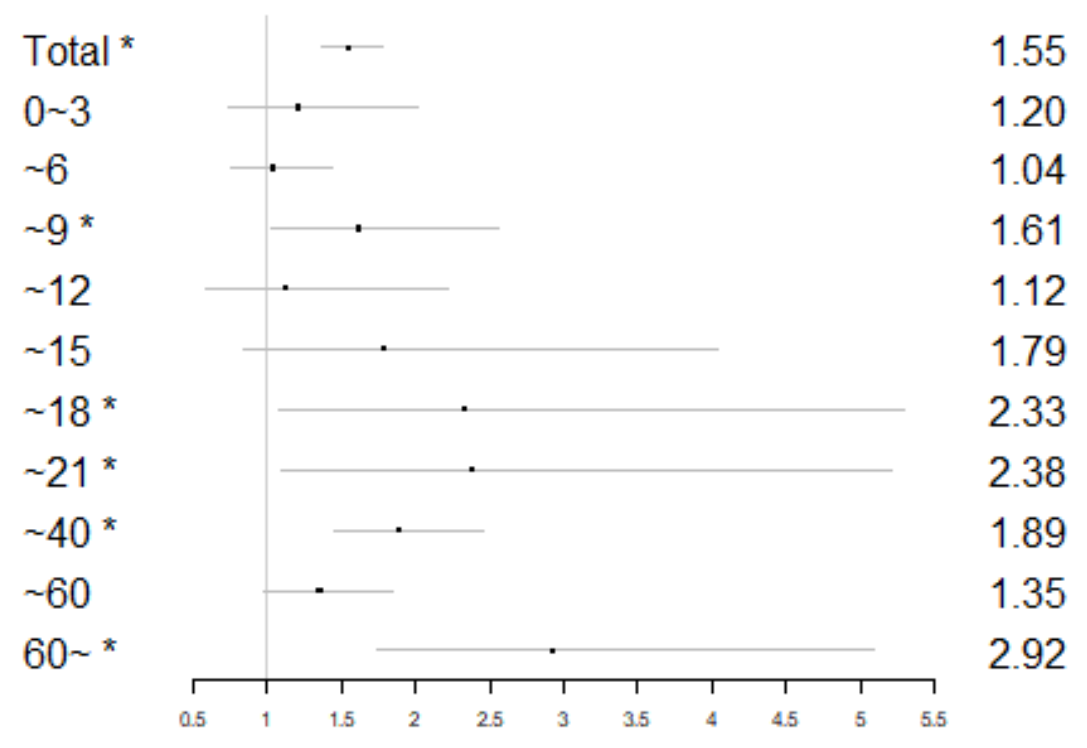


f1

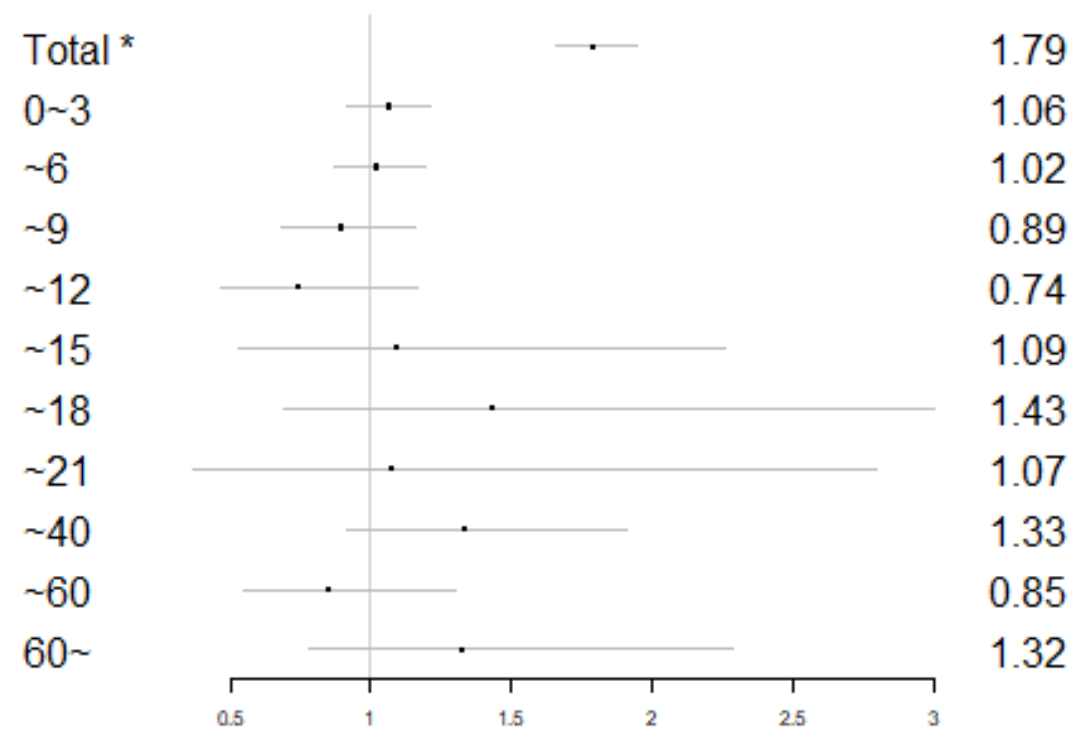

f2

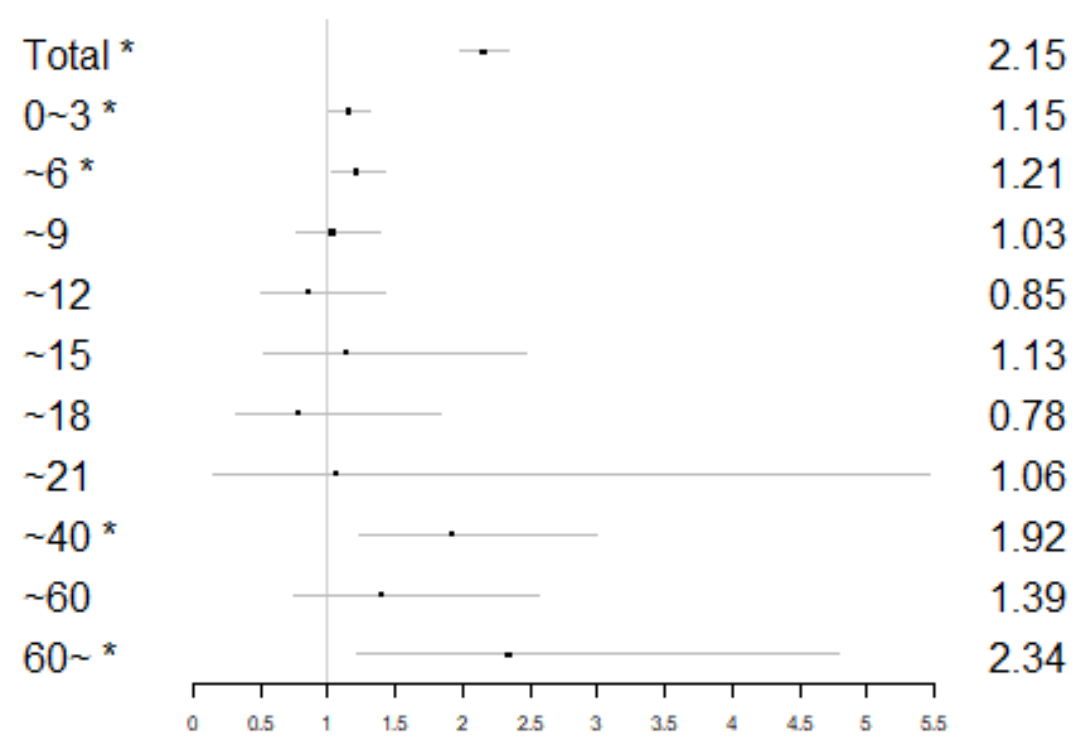


f23

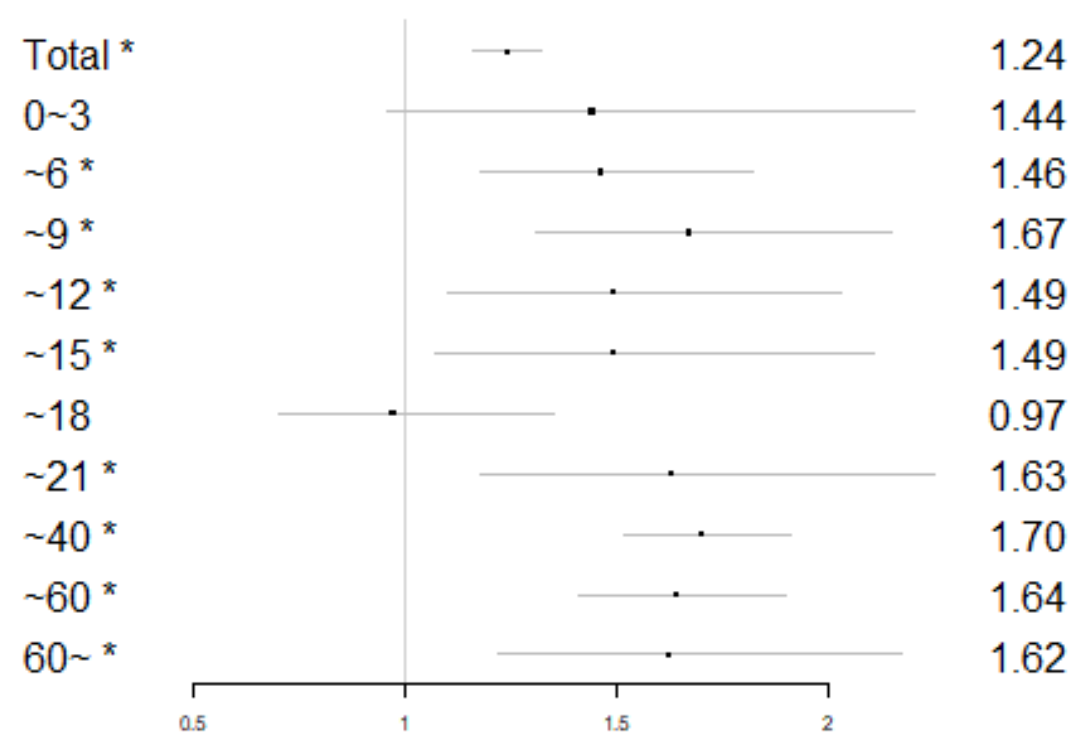

f24

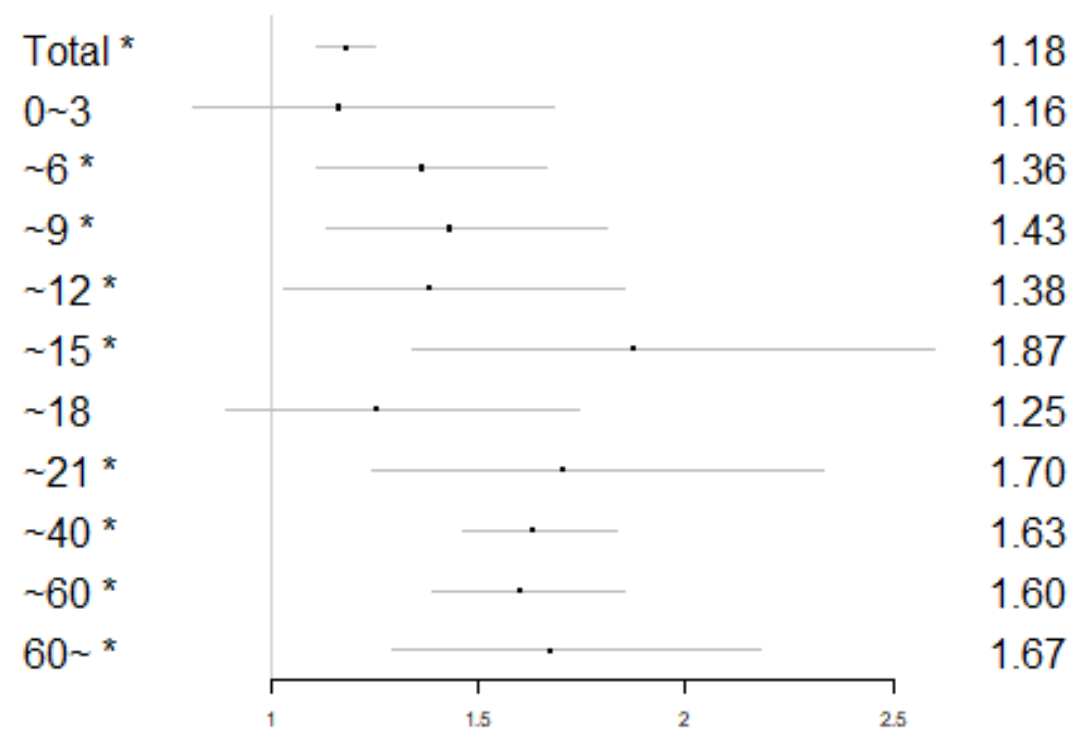

Figure 2. Forest plot for the OR of male to female subjects in each age group. (OR are displayed in the right column and age groups in the left panel for each allergen. *: p value<0.05; d1: House dust mite, i6: German cockroach, tx4: Tree pollen mix, e5: Dog dander, mx1: Mold mix, f1: Egg whites, f2: Cow's milk, f23: Crab, f24: Shrimp) 

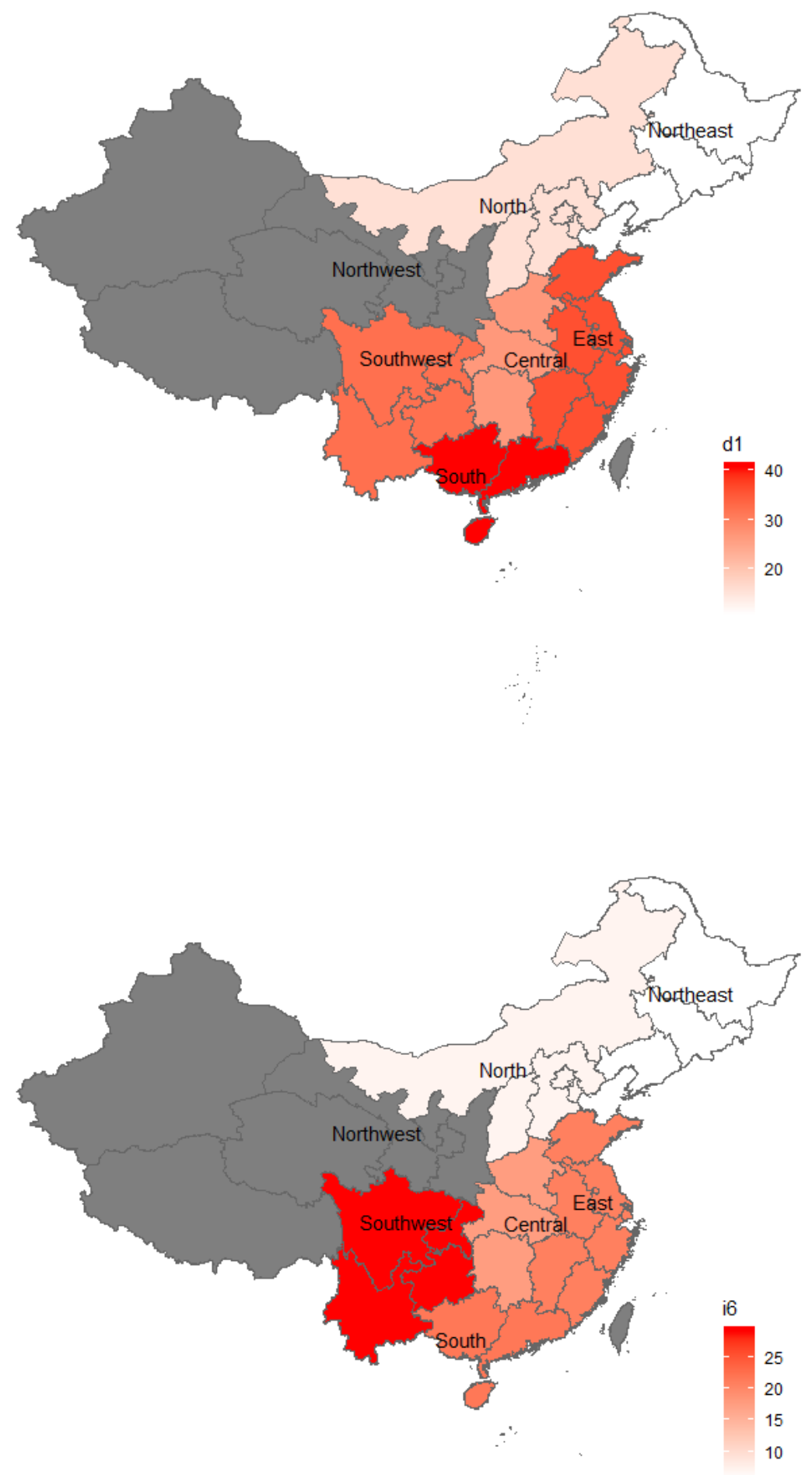

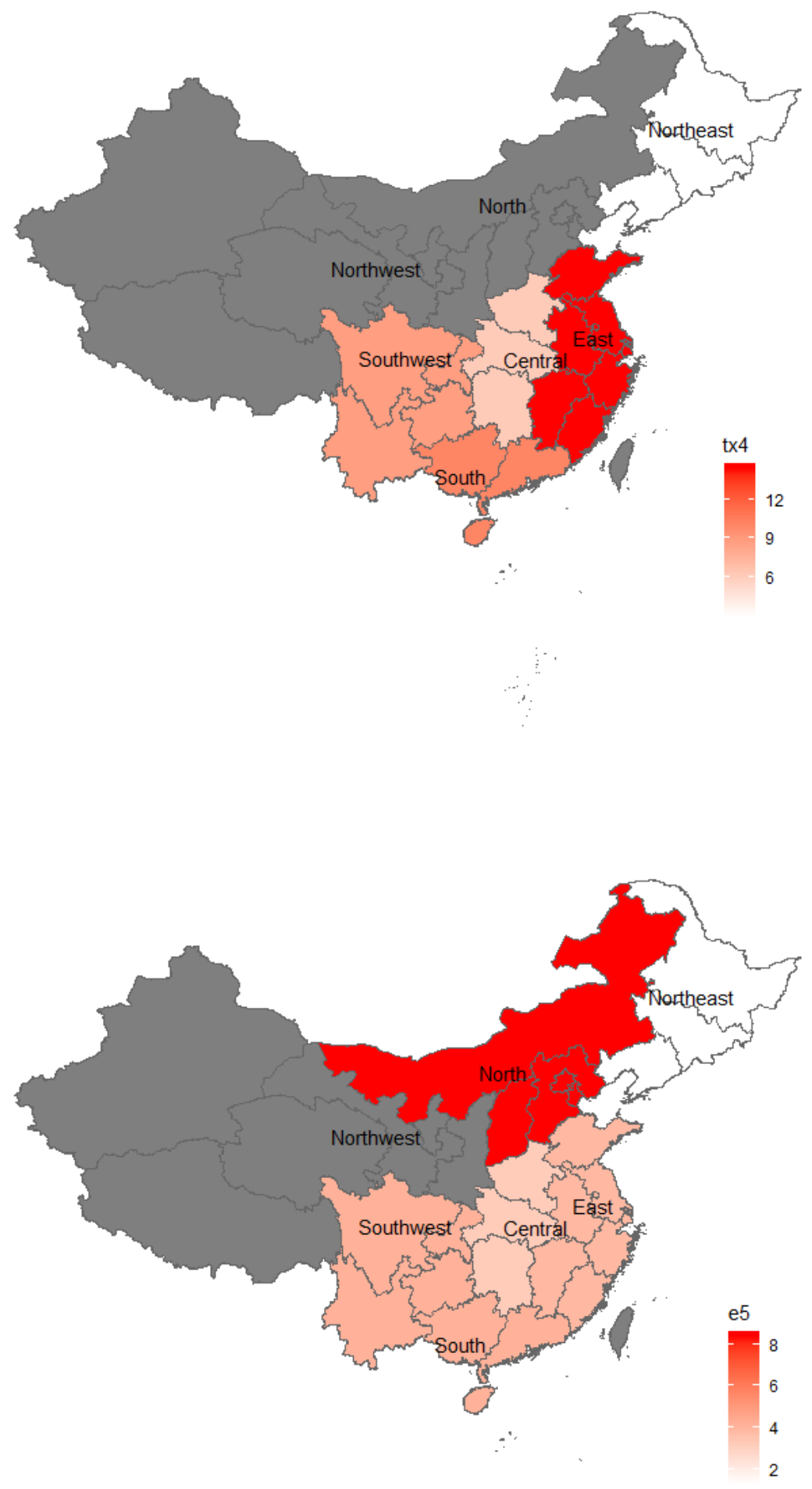

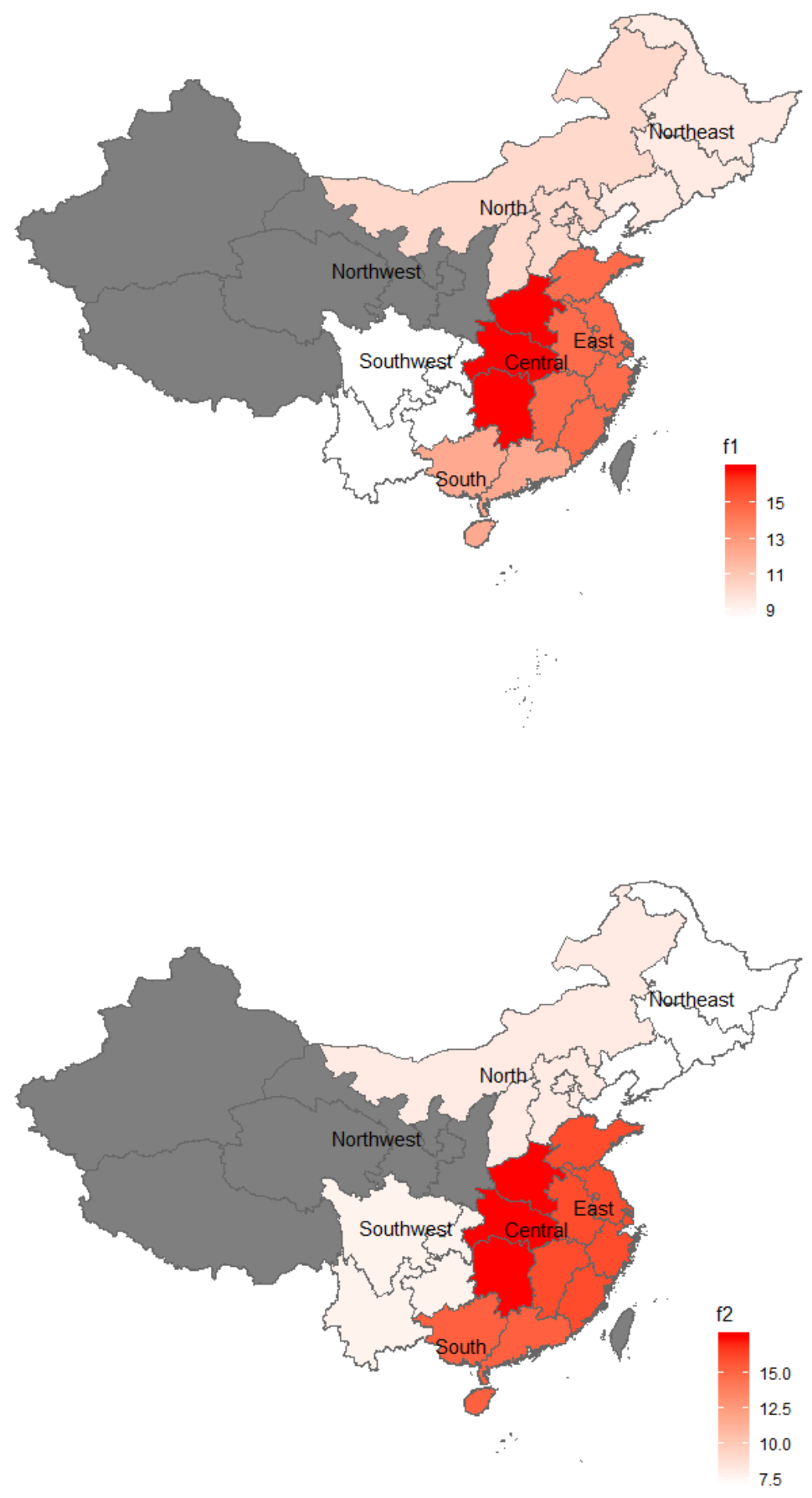

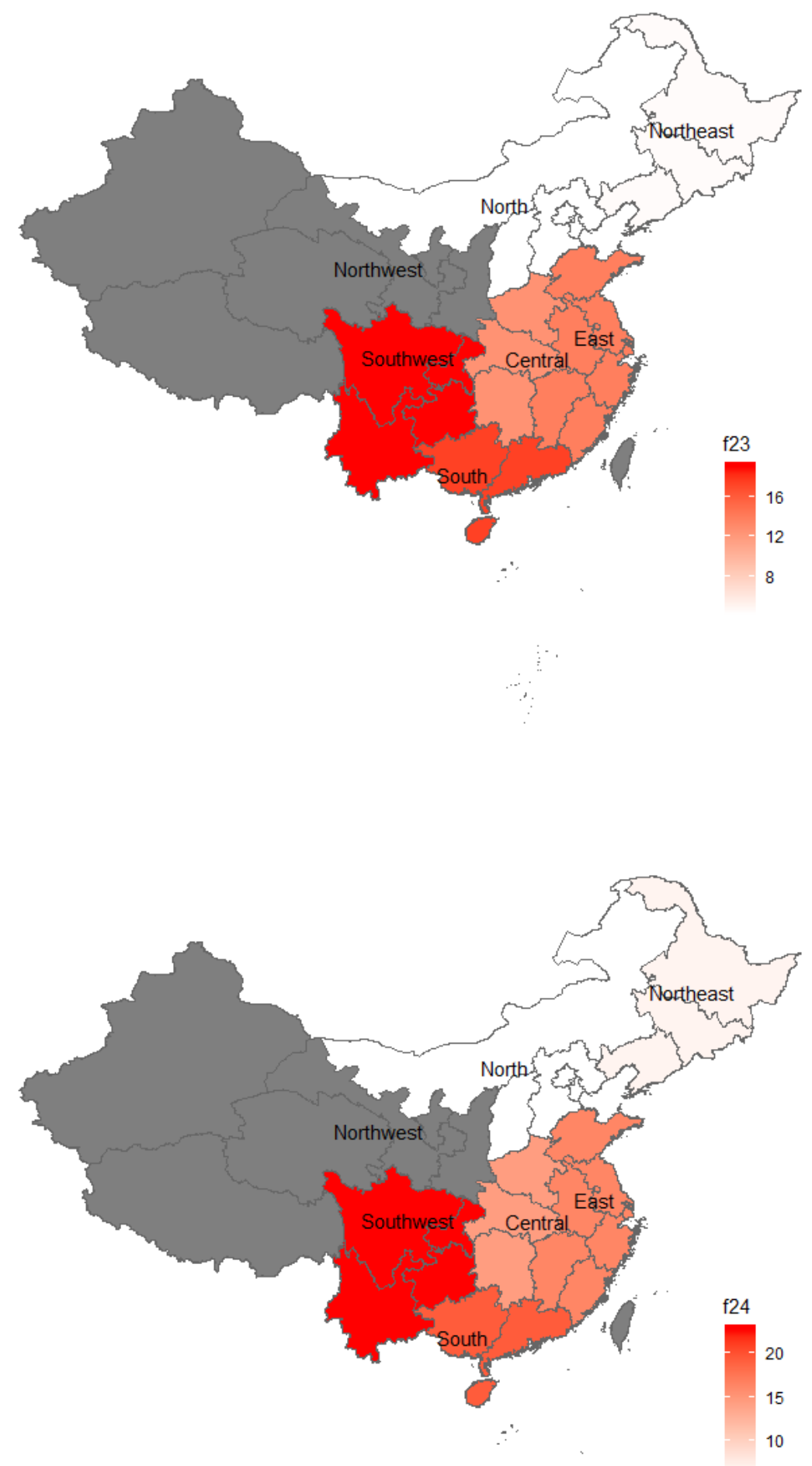
Figure 3. Heatmap for the prevalence of positive SIgE tests for allergens in different regions. From left to right, top to bottom, the figures are the results of d1: House dust mite, i6: German cockroach, tx4: Tree pollen mix, e5: Dog dander, f1: Egg whites, f2: Cow's milk, f23: Crab, f24: Shrimp. (The deeper the red is, the higher the prevalence. The number of the total cases in Northwest China for all 9 allergens and in North China for txy were less than 50, so the prevalence in those regions was not calculated. The maps were generated by using $R$ studio 3.6.2)

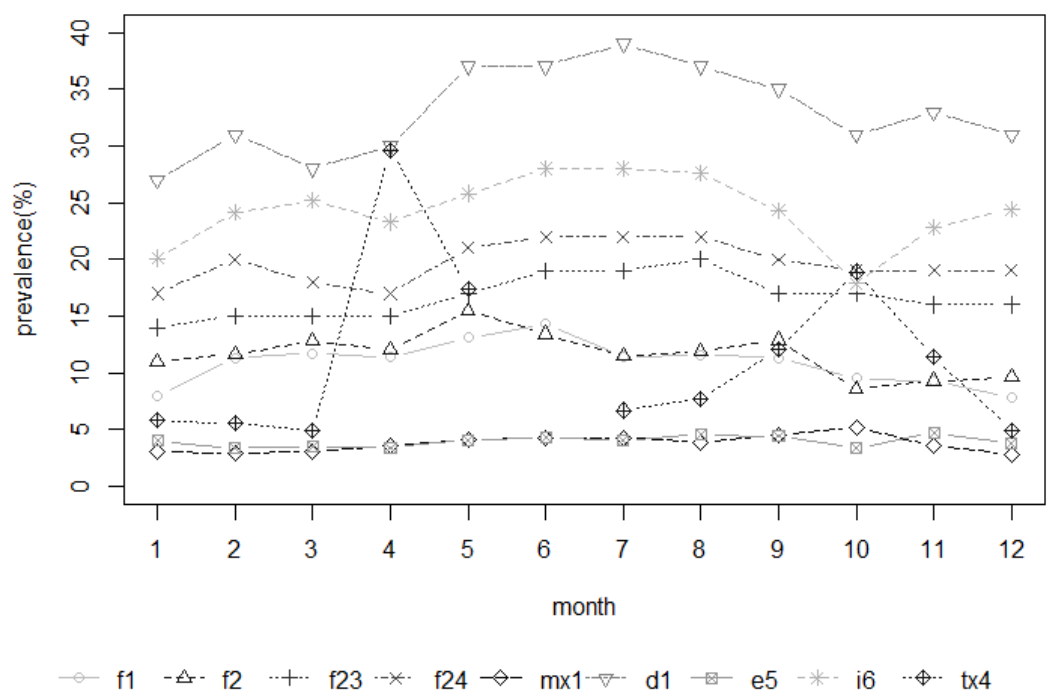

Figure 4. SIgE reactivities to allergens in patients in different months. (f1: Egg whites, f2: Cow's milk, f23: Crab, f24: Shrimp, d1: House dust mites, mx1: Mold mix, e5: Dog dander, i6: German cockroach, tx4: Tree pollen mix; data for tx4 in June are missing) 